\title{
The validation of the dynamic food chain model BURN-POSEIDON on Cs-137 and Sr-90 data of the Dnieper-Bug estuary, Ukraine
}

\author{
R. Heling ${ }^{1}$ and R. Bezhenar ${ }^{2}$ \\ ${ }^{1}$ Nuclear Research and consultancy Group (NRG) P.O. Box 9034, 6800 ES Arnhem, \\ The Netherlands \\ ${ }^{2}$ Ukrainian Centre of Environmental and Water Projects, Kiev, Prospect Glushkova 42, \\ Kiev, 03187, Ukraine
}

\begin{abstract}
The uptake of radioceasium and radiostrontium in biota in dose assessment models is mostly estimated on the basis of Concentration Factors (CF). For accidental releases, the dynamical foodweb model BURN has been implemented in the coastal model POSEIDON (part of the Decision Support System RODOS). BURN can be applied on water bodies with different salinity levels, since in the model the uptake of radioceasium and radiostrontium in phytoplankton is governed by potassium and calcium in the water, which are calculated via the easier-to-obtain parameter salinity. Recently a dataset on radiocaesium and radiostrontium has been collected for various aquatic organisms in the Dnieper-Bug Estuary (DBE) in Ukraine, which enabled model validation with BURN. Considering the limitation of compartment models and the fact BURN is a predictive model, with fixed model parameters, the model results are within a reasonable range with the measurement data. Besides comparison with measurement data, the model calculations were also used to derive values for $\mathrm{CF}$ and compared with literature, which gave reasonable results for Cs-137 in fish and molluscs. For Sr-90 however, the calculated values exceeded the levels given in literature, since equilibrium between radionuclides in biota and water is not reached. Longer time periods for the radionuclide flux into the DBE, both from the Dnieper and the Black Sea are required to obtain high quality model results for the years after 1989.
\end{abstract}

\section{INTRODUCTION}

This study presents a validation test of biological radionuclide uptake model BURN (part of the compartment model for European coastal waters POSEIDON with the DSS RODOS) on the Dnieper South-Bug estuary (Ukraine) for radiocaesium and radiostrontium with recently acquired data sets for radioactivity concentration in biota and water in the different regions of the DBE [1] compiled by Hydrometeorological Institute in Ukraine (with support of the IAEA).

The dynamical uptake model BURN for biota had been implemented earlier into the POSEIDON system to substitute the Concentration Factors (CF) approach - for aquatic organisms in seas and coastal regions, to assess the activity concentration of radionuclides in biota after accidental releases [2, 3]. The reason is that in the case of accidental releases, there is no equilibrium between water and biota, especially in small coastal compartments and (parts of) estuaries. Using the CF approach this results in either over- or underpredictions of the radionuclide concentration in organisms. BURN is then applied to assess the radionuclide activity concentration in the various trophic levels. The model BURN was improved by submodels to govern the uptake of radioceasium and radiostrontium [3] by phytoplankton - for Cs-137 and Sr-90, and in gills, for Sr-90, on the basis of the presence of competitive ions potassium $\left(\mathrm{K}^{+}\right)$and calcium $\left(\mathrm{Ca}^{2+}\right)$ in the seawater respectively. For the gills, the uptake rate for Cs-137 is not modified for the marine environment, since it has a relatively minor contribution to the uptake of Cs-137 in marine fish in comparison with Sr-90, which shows hardly biomagnification. For phytoplankton, both the uptake for Cs-137 and for Sr-90 is governed by the cation concentration of 
the competitive ions, for Cs-137 due to the transfer within the foodweb this is more relevant than for Sr-90 with less biomagnification within the foodchain.

This allows the application of the dynamical food chain model in various saline conditions, since the coastal regions of Europe, to which the POSEIDON model has been applied, have a large range of salinity. When often the information on $\mathrm{K}^{+}$and $\mathrm{Ca}^{2+}$ is lacking, a sub-model was implemented in BURN to relate the concentrations of these cations with the easy-to-obtain parameter salinity. This was tested among others on the Dnieper Bug Estuary (DBE) in 2008 [4]. In 2011 a data sets on radiocaesium and radiostrontium became available from the Institute of Hydro-meteorology in Ukraine [1].

This data set contains both concentration of radiocaesium and radiostrontium in the DBE from 19861993 in 11 different biological species, mostly fish, in different locations of the DBE. This unique data set made it possible to test the predictive model BURN in a field study. Since the BURN is a predictive and simplified model to be used in a large range of different coastal regions, including estuaries, the model cannot be controlled by calibration parameters. Comparison with measurement data will demonstrate whether this simplified approach, based on a standard foodweb, is sufficient for a reasonable assessment of the radionuclide concentration in biota after accidental releases. The model results are compared with data sets. Afterwards, the $\mathrm{CF}$ values are calculated to be compared with literature values to get an idea whether these value are comparable with the values assessed by the BURN model.

\section{APPLICATION OF POSEIDON - BURN ON THE DNIEPER BUG ESTUARY}

The BURN model has fixed parametrisation for uptake parameters in aquatic organisms (respiration rates, growth rates, food web composition), and is related as much as possible to environmental conditions such as salinity. The biological uptake model BURN for marine organisms is based on accumulation of radionuclides into the target tissue, and has consumption rates based on growth and respiration, and the retention times of a radionuclide within the organism are related to the residence time of a specific radionuclide in the target tissue. Parameters such as biological half life, respiration rate, and growth rate are kept constant, on the basis of calibration of this the foodchain model in earlier studies. In this study it is not possible to tune the model, since all parameters are based on environmental parameters or on fixed biological half lives. Therefore this validation is in fact a test to see whether reasonable results can be expected with a model intended to give best estimates more than conservative values, for radioactivity concentrations in aquatic biota after accidental releases.

The Dnieper Bug Estuary is located in the southern Ukraine, and receives water from both the Dnieper and the Bug River. After the Chernobyl accident the estuary received the main fraction of its radiocaesium from the Black Sea via the Strait of Kinbourn, due to the Chernobyl fallout on the Black Sea; the more mobile radiostrontium entered mainly the estuary via the Dnieper River [5], since it is more mobile than caesium. The major fraction Cs-137 was transferred to the bottom sediments in the subsequent reservoirs of the Dnieper River before it could reach the DBE. Model tests with POSEIDON for a standard discharges have been presented in an earlier study [4]; the current model application focuses on the validation with measurement data concerning radiocaesium and radiostrontium levels in biota in the DBE.

Measurements data on Sr-90 and Cs-137 were made available by the IAEA, a collection of data sets for the Dnieper - Bug estuary supplied from various institutes in Ukraine - UHMI (Ukrainian Hydrometeorological Institute), and IBSS (Institute for Biology of the Southern Seas, Sevastopol), and IHB (Institute of Hydrobiology). The database as compiled by IHMI contains about 180 records, for both the abiotic and biotic part of the DBE, for the period 1986-1992; about 50 records on about 11 different species (pike, roach, bullhead, bream among others). Data on radioceasium and radiostrontium for fish were from the locations Kherson, at the mouth of Dnieper River, with a low salinity of about $1 \mathrm{~g} / \mathrm{L}$, from west of Kherson, in the Dnieper delta just before the DBE inflow (Kizomis), and from a location near the town of Stanislav, at the boundary of a sub-basin at the east part of the DBE, with a salinity of $2-5 \mathrm{~g} / \mathrm{L}$ 


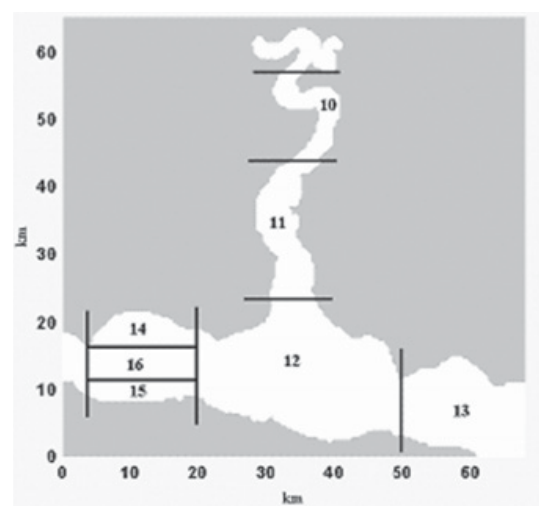

Figure 1. The planar structure of DBE subdivision. Most radionuclide data for biota are from the compartments 13 , some measurements are from compartment 12 .

Table 1. The implication of different salinity levels on the values for CF (phytoplankton) for Sr-90 and Cs-137, and for the gill extraction coefficient $b(\mathrm{Sr}-90)$ as calculated by the submodels of BURN. The value for the gill extraction for Cs-137 is kept constant at $10^{-3}$ independent from the salinity.

\begin{tabular}{|l|l|l|l|}
\hline \multirow{2}{*}{ Location (salinity, g/L) } & \multicolumn{2}{|l|}{ CF (phytoplankton) L/kg } & Gill extraction coefficient b [-] \\
\cline { 2 - 4 } & Sr-90 & Cs-137 & Sr-90 \\
\hline West DBE $(\mathrm{S}=11)$ & 130 & 32 & $0.1410^{-3}$ \\
\hline East DBE $(\mathrm{S}=1)$ & 224 & 253 & $1.7010^{-3}$ \\
\hline
\end{tabular}

(see figure 1). A number of measurements are indicated as located in DBE (IHB) - but considering the fact these are freshwater species, the location is assumed to be in the eastern part of the estuary. High salinity in the estuary is found as expected on the bottom layer in the fairway of the DBE. So a few measurements are from the centre of the estuary, no biota measurements were available from the western and most saline part of the DBE close to the Black Sea. For comparison with the POSEIDON model, the fish species have been grouped in predatory and non-predatory fish, and averaged for each year. Figure 1 shows the compartment structure of the DBE.

The salinity driven uptake model in BURN governs the uptake rates in the various aquatic organisms - for Cs-137 it regulates the uptake in phytoplankton, and for Sr-90 both the uptake in phytoplankton and in fish, the latter via the uptake of the radionuclide a the gills, inversely proportional with the salinity, see [4]. The equations of the potassium and calcium concentration on the basis of salinity are given here:

$$
\begin{gathered}
K^{+}=11.6 \cdot S-4.28 \quad\left(\mathrm{~K}^{+}>1.5 \mathrm{mg} / \mathrm{L}, \mathrm{S}>0.14\right) \\
C a^{2+}=11.6 \cdot S+9.5 \quad\left(\mathrm{Ca}^{2+}>15, \mathrm{~S}>0.5\right)
\end{gathered}
$$

In table 1 the calculated values for $\mathrm{CF}$ (phytoplankton) for ${ }^{137} \mathrm{Cs}$ and ${ }^{90} \mathrm{Sr}$ and for the gill extraction coefficient $(b)$ for fish both for the area with the highest salinity, the Kinbourn Strait in the western part, and for the area with the lowest salinity, close to the outflow near Kherson in the eastern part, are given.

In table 2 the calculated concentration is given, and compared with measurements in the estuary. A comparison of the prediction on the basis salinity by means of the sub-models and measurements are given in table 2 . From table 2 it can be seen that the empirical model to predict the competitive ions important for Cs-137 and Sr-90 are generally acceptable in terms of trend, however more tests for this sub-module should be performed. 
Table 2. Calculated $\mathrm{Ca}^{2+}$ and $\mathrm{K}^{+}$concentration by the salinity sub-model in BURN, for the compartments of the DBE, compared with measurement data on $\mathrm{K}^{+}$and $\mathrm{Ca}^{2+}$.

\begin{tabular}{|c|c|c|c|c|c|}
\hline \multirow{2}{*}{ Compartment } & \multirow{2}{*}{ Salinity g/L } & \multicolumn{2}{|c|}{$\mathbf{C a}^{2+} \mathbf{~ m g / L}$} & \multicolumn{2}{c|}{$\mathbf{K}^{+} \mathbf{~ m g / L}$} \\
\cline { 3 - 6 } & & Model & Measurement & Model & Measurement \\
\hline 10 & 1 & 21.1 & 85.6 & 7.32 & 20.2 \\
\hline 11 & 3 & 44.3 & 76.8 & 30.52 & 37.4 \\
\hline 12 & 5 & 67.5 & - & 53.72 & - \\
\hline 13 & 1 & 21.1 & - & 7.32 & - \\
\hline 14 & 7 & 90.7 & 75.6 & 76.92 & 20 \\
\hline 15 & 7 & 90.7 & - & 76.92 & - \\
\hline 16 & 11 & 137.1 & - & 123.32 & - \\
\hline
\end{tabular}
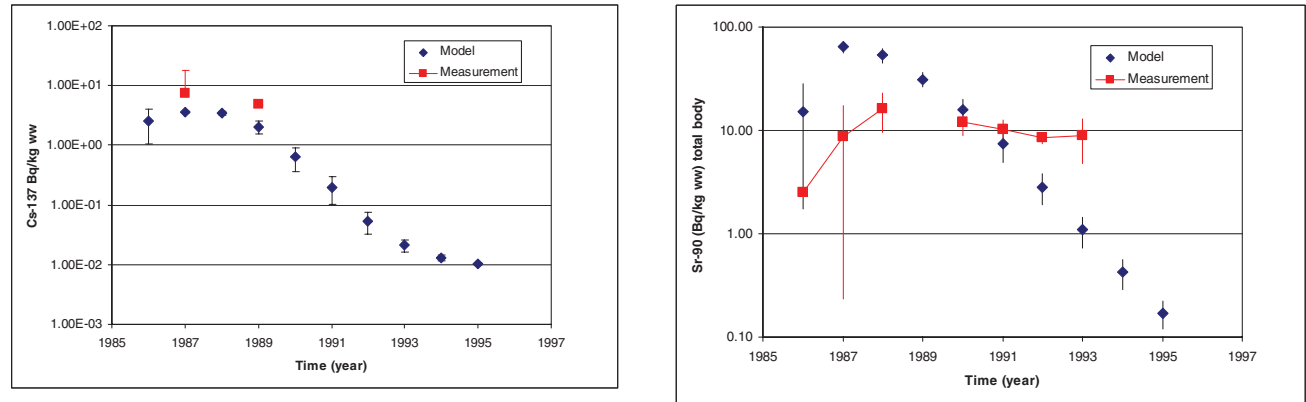

Figure 2. Prey fish. Left-hand graph: Cs-137, compartment 12; right - hand graph: Sr-90 compartment 13.
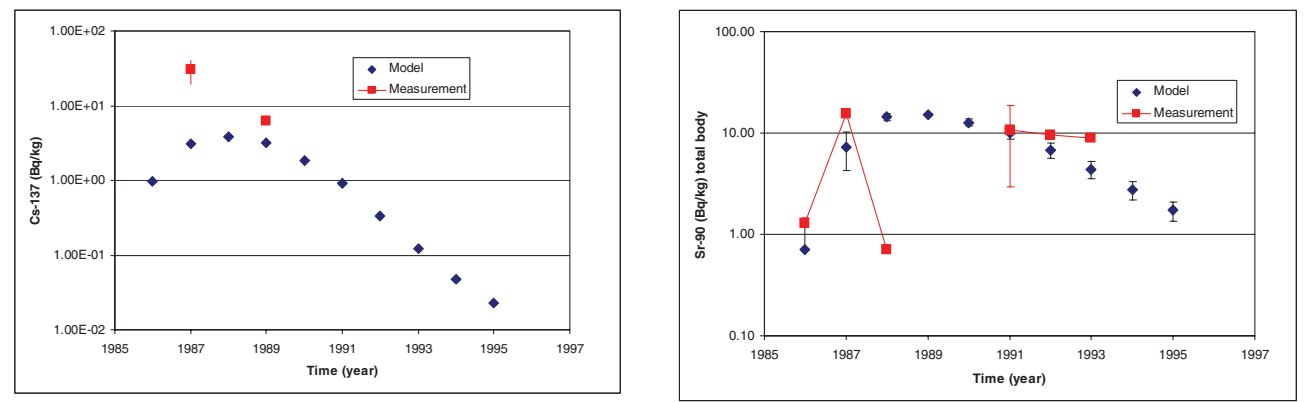

Figure 3. Predatory Fish. Left-hand graph: Cs-137, compartment 12, right hand side, Sr-90 compartment 13.

\section{RESULTS AND DICUSSION}

The following figures show a selection of results for the application of POSEIDON-BURN on the DBE for prey fish (figure 2), predator fish (figure 3), and molluscs (figure 4).

For Sr-90 a slight overestimation of the model results can be observed, for Cs-137 there is a slight underestimation. The explanation however is not evident, for Sr-90 there is the possibility of uncertainty range in the samples; the exact sample treatment procedures should be investigated further in detail. From graphs with the predicted levels for $\mathrm{Sr}-90$ can be seen that radionuclide concentration in fish drops faster than the measurements indicate. The reason can be an underestimation of the Sr-90 levels in water. Comparison of the predicted levels of the Sr-90 concentration in water in the Dnieper mouth and the measurements in the water showed that the pulse declined quicker in the model than in reality; the pulse used as input was based on extrapolation of the $\mathrm{Sr}-90$ pulse in the Dnieper in the first two - three 

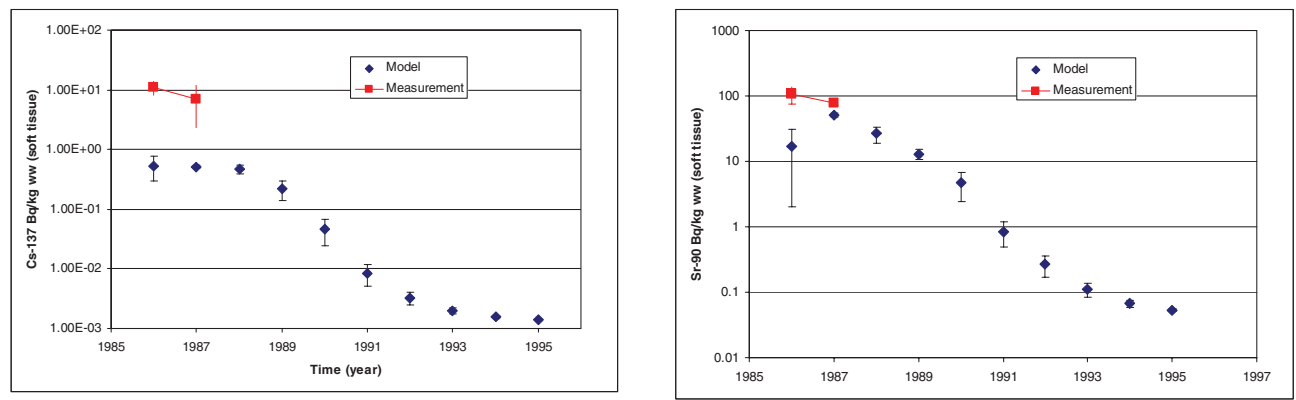

Figure 4. Molluscs. Left hand graph: Cs-137, compartment 12, right- hand side compartment 12, Sr-90.

years after the accident. Better data sets for water concentration in the Dnieper mouth of the six years after would be necessary to get better predictions for the biota. For biota there were sufficiently long timeseries up to 1995 , in contrast to the water, which had shorter series, up to 1989 . These data should be collected.

For Cs-137 the model results for fish and molluscs are slightly lower than the measurements; the reason might be that the model has a very large compartment in the Black Sea, next to the DBE, and Cs-137 deposited upon that compartment is diluted in a relatively large volume, whereas in real the fall-out on the Black Sea near the estuary gives a relative large pulse into it. This absence of this pulse is due to the constraints of compartment models; in this case the nearby Black Sea compartment should have had more regional compartments to deal with this local deposition of radioceasium entering the Dnieper Bug Estuary.

Another way to evaluate the model results is by comparing the ratio of the predicted radionuclide concentration in fish towards the predicted radionuclide concentration from BURN, with the CF values derived from the measurements. Finally these predicted CR values can be compared with literature values for both the freshwater and the marine environment.

The calculated CF values for Cs-137 for fish derived from the model are about $700 \mathrm{~L} / \mathrm{kg}$ for the freshwater compartments; literature gives a value of $800 \mathrm{~L} / \mathrm{kg}$ [6], the averaged $\mathrm{CF}$ - value for the measurements is about $130 \mathrm{~L} / \mathrm{kg}$. For the compartments with the highest salinity, the modeled $\mathrm{CF}$ is $240 \mathrm{~L} / \mathrm{kg}$; literature values for the marine environment are around $100 \mathrm{~L} / \mathrm{kg}[6,7]$. For mollusks the modeled CF for Cs-137 is about $34 \mathrm{~L} / \mathrm{kg}$ for the freshwater compartments, and $16 \mathrm{~L} / \mathrm{kg}$ for more saline compartment. The measurements indicate some higher value of about $140 \mathrm{~L} / \mathrm{kg}$. Literature gives slightly higher values of $85 \mathrm{~L} / \mathrm{kg}$ for the freshwater environment and $40 \mathrm{~L} / \mathrm{kg}$ for the marine environment. The BURN model gives smaller values here.

For Sr-90 the literature value for CF for freshwater fish is about $20 \mathrm{~L} / \mathrm{kg}$ [6], identical to the calculated values from the measurement. The model however due the relatively large half lives values in fish gives higher values of $1200 \mathrm{~L} / \mathrm{kg}$ for freshwater fish. For the marine environment the value is about $3 \mathrm{~L} / \mathrm{kg}$ according to literature [6,7], the model gives for the high saline compartment values of about $400 \mathrm{~L} / \mathrm{kg}$. The estimated relatively high half lives in the BURN model cause that there is no equilibrium between the dissolved Sr-90 in the water, and Sr-90 in fish. This is also caused by the relatively rapid decline of Sr-90 predicted by the model due to the rapid decline of Sr-90 in the Dnieper pulse. This causes that $\mathrm{Sr}-90$ in fish is not in equilibrium with concentration in the surrounding water. In real the Sr-90 concentration in the river might have declined slower, causing ecological retention times for fish in the DBE comparable with the hydrological retention time.

For molluscs the calculated CF values for Cs-137 are slightly lower than the measured values. For freshwater, the modelled value is $34 \mathrm{~L} / \mathrm{kg}$, and $80 \mathrm{~L} / \mathrm{kg}$ according to literature [6]. For the marine compartment, the calculated value is about $16 \mathrm{~L} / \mathrm{kg}$, whereas the literature gives for saline conditions a value of $40 \mathrm{~L} / \mathrm{kg}[6,7]$. The measurements give a value for the freshwater compartments of $140 \mathrm{~L} / \mathrm{kg}$. For 
Sr-90 the modelled value is about $1000 \mathrm{~L} / \mathrm{kg}$, whereas the measurements indicate a value of $700 \mathrm{~L} / \mathrm{kg}$. Literature gives a value of $200 \mathrm{~L} / \mathrm{kg}$ [6], lower than both the model - based value as the measurementbased $\mathrm{CF}$ value. For the saline environment of the DBE, the calculated CF for molluscs is about $200 \mathrm{~L} / \mathrm{kg}$, whereas literature gives about $10 \mathrm{~L} / \mathrm{kg}$.

\section{CONCLUSION}

- Application of the BURN model on the Dnieper- Bug Estuary demonstrates that the prediction matches the data measurements sufficiently: comparison of model results with measurement data gave reasonable results for prey fish, predatory fish and mollusc in Dnieper Bug Estuary. The BURN model is aimed for predictive modelling in decision support systems and fits is purpose for decision support systems since the results are in reasonable range with the model results.

- Important to obtain reliable results for radioactivity in biota in the DBE, is to have reliable input data on the fluxes into the DBE. To get the influx of radionuclides from the Black Sea into the DBE, the introduction of extra local compartments in the Black Sea near the DBE, based on fallout maps, is necessary. Concerning the Sr-90 and Cs-137 influx from the Dnieper River into the DBE, additional time series extended for the years after 1989, are needed to introduce in the BURN model as input parameter.

\section{Acknowledgements}

The authors are grateful to have received a compilation of measurement data on radiocaesium and radiostrontium in biota of the Dnieper-South-Bug, composed by G.V. Laptev (Ukrainian Scientific \& Research Institute for Hydrometeorology, Department of Monitoring of Radioactivity in the Environment). This data set contains also measurement data collected by IBSS (Institute for Biology of the Southern Seas, Sevastopol), and IHB NAS (Institute of Hydrobiology, NAS, Kyiv).

\section{References}

[1] A.G Laptev. DBE-06. The Dnieper-South Bug Biota Scenario Description. Ukrainian Scientific \& Research Institute for Hydro-meteorology, Department of Monitoring of Radioactivity in the Environment. With permission of the IAEA (D. Telleria). 2011.

[2] Veleva, B., Koziy, L., Yushchenko, S., Maderich, V., Mungov, G. Radioprotection 37 (2002). C1-827-C1-832.

[3] Heling R. Koziy L. Bulgakov V. Radioprotection 37 (2002) C1-833-C1-838.

[4] Heling, R, Bezhenar R. Radioprotection 44 (2009) 7410-746.

[5] N. Margveleshvilii, V. Maderich, M. Zheleznyak. J. of Env. Rad. 43 (1999) 1570-171.

[6] Coughtrey P.J., Thorne M.C. Radionuclide Distribution and transport in Terrestrial and Aquatic Ecosystems, A Critical Review of Data, Vol 1. A.A Balkema, Amsterdam, 1983.

[7] Technical Report Series, no. 422. Sediment Distribution Coefficients and Concentration Factors for Biota in the Marine Environment. International Atomic Energy Agency, Vienna, 2004. 